\title{
Blue and White LED Lights Enhance Biosynthesis of Rosmarinic Acid in Cell Culture of Agastache rugosa
}

\author{
${ }^{1}$ Woo Tae Park, ${ }^{1}$ Sun Kyung Yeo, ${ }^{2}$ Nam Su Kim, ${ }^{3}$ Jae Kwang Kim and ${ }^{1}$ Sang Un Park \\ ${ }^{1}$ Department of Crop Science, Chungnam National University, 99 Daehak-ro, Yuseong-gu, Daejeon 34134, Korea \\ ${ }^{2}$ Forest Medicinal Resources Research Center, National Institute of Forest Science, Yeongju 36040, Korea \\ ${ }^{3}$ Division of Life Sciences and Bio-Resource and Environmental Center, Incheon National University, Incheon 22012, Korea
}

\author{
Article history \\ Received: 11-02-2020 \\ Revised: 13-05-2020 \\ Accepted: 23-05-2020 \\ Corresponding Author: \\ Sang Un Park \\ Department of Crop Science, \\ Chungnam National \\ University, 99 Daehak-Ro, \\ Yuseong-Gu, Daejeon 34134, \\ Korea \\ Email: supark@cnu.ac.kr \\ Jae Kwang Kim \\ Division of Life Sciences and \\ Bio-Resource and \\ Environmental Center, Incheon \\ National University, Incheon \\ 22012, Korea \\ Email: kjkpj@inu.ac.kr
}

\begin{abstract}
Agastache rugosa, an herbaceous Korean perennial, contains pharmacologically important phenylpropanoids such as tilianin and rosmarinic acid. However, the knowledge of biosynthesis of phenylpropanoids from A. rugosa is limited. Therefore, a study was conducted to develop an efficient protocol for in vitro regeneration of $A$. rugosa and to investigate the influence of three different LED light wavelengths (white, blue and red) on the biosynthesis of phenylpropanoids, including altered gene expression and variance in rosmarinic acid accumulation in calli. Transcription analyses revealed that white LED light enhances $R A S$ expression; transcript levels were 15.7- and 10.4-fold higher for calli treated with white LED light than for those treated with red and blue light, respectively. Similarly, $H P P R$ and $C 4 H$ were also more highly expressed under blue and white LED light. In addition, HPLC quantification assays indicated that the highest levels of rosmarinic acid accumulate in calli treated with blue, red and white light (in that order) one week after cultivation. Together, our gene expression and HPLC quantification results provide evidence that rosmarinic acid in A. rugosa increases with the application of various wavelengths of LED light.
\end{abstract}

Keywords: Agastache rugose, Light Emitting Diode, Phenylpropanoid, Rosmarinic Acid, Gene Expression

\section{Introduction}

Medicinal plants and botanicals play an important role in substitutive health care services. Recently, scientific interest in the treatment of infectious and degenerative diseases has focused on novel bioactive metabolites derived from medicinal plants, as they have fewer side effects than synthetic therapeutic compounds (Glorybai et al., 2015). World Health Organization (WHO) reports have claimed that $80 \%$ of healthcare practices in developing countries use traditional plant extracts (WHO, 2002). The molecules identified in medicinal plants have been used in the treatment of cancer, diabetes, liver disorders, hypertension and cardiovascular diseases (Rejiniemon et al., 2014). However, the decline in medicinal plant populations has been exacerbated by global warming and other anthropomorphic phenomena, increasing interest in the identification and protection of traditional medicinal plants for various applications (Abdullah Al-Dhabi et al., 2015). Agastache rugosa (Fig. 1), a common medicinal plant grown in the East Asian countries of Korea, Japan and China, as well as Siberia in Russia, belongs to the mint family (Labiatae). Agastache rugosa contains several types of secondary metabolites including diterpenes, triterpenes, polyphenols, flavonoids, carotenoids, sesquiterpenes and essential oils (Choi and Lee, 1999; Yamani et al., 2014). Essential oils are used in the treatment of fungal infections caused by human and animal fungal pathogens (Gundidza, 1993), other metabolites have antiviral, antibacterial, antifungal and anticancer properties (Min et al., 1999; Hong et al., 2001; Song et al., 2001; Shin and Kang, 2003); still other metabolites, such as rosmarinic acid and tilianin, derived from the phenylpropanoid pathway, exhibit antimicrobial, antiviral, antioxidant, anti-inflammatory, antihypertensive, antiatherogenic and vasorelaxant effects (Hong et al., 2001; Gao et al., 2005; Nam et al., 2006; Swarup et al., 2007; Hernández-Abreu et al., 2009; Al-Dhabi et al., 2014).

The biosynthesis of phenylpropanoids involves the initial precursor molecule phenylalanine. The presumed 
pathway for the synthesis of rosmarinic acid in A. rugosa is shown in Figure 2. Para coumaroyl-CoA, produced from cinnamic acid by the catalytic action of cinnamate 4-hydroxylase (C4L) and 4-coumarate-CoA ligase (4CL), is the backbone for the synthesis of flavonols, isoflaconoids and anthocyanins. Tilianin is synthesized by the sequential action of the enzymes chalcone synthase (CHS), chalcone isomerase (CHI), flavone synthase, apigenin 4'-O-methyltransferase and glucosyl transferase, whereas rosmarinic acid is synthesized from intermediate compounds, including 4-coumarayl-CoA, 4-hydroxyphenyllactic acid, caffeoyl-4hydroxyphenyllactic acid and 4-coumarotil-3,4dihydroxyphenyllactic acid (Kuroki and Poulton, 1981; Petersen, 1991; 1997; Ogata et al., 2004; Martens and Mithöfer, 2005; Vogt, 2010; Jiang et al., 2006; Li et al., 2006; Zhao et al., 2013).

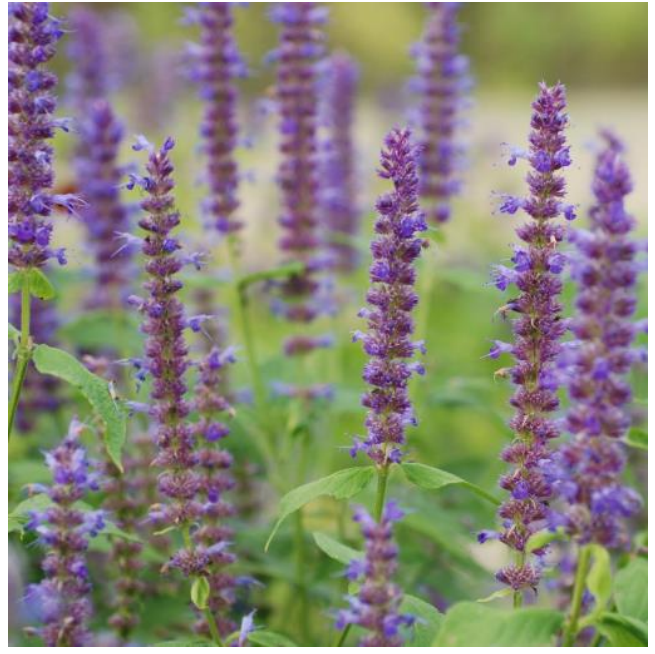

Fig. 1: Pictures of Agastache rugosa

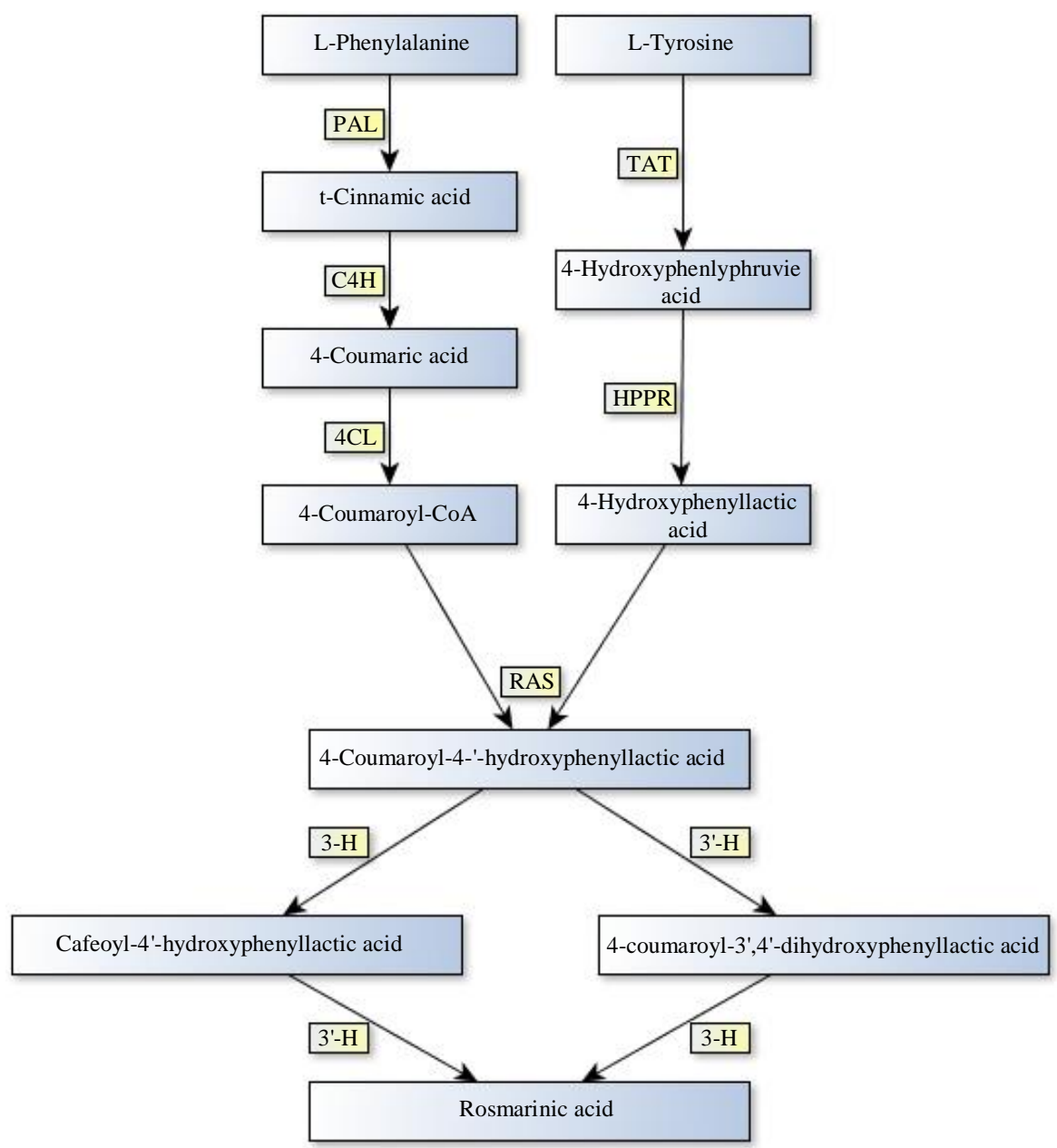

Fig. 2: Proposed biosynthetic pathway of rosmarinic acid. $P A L$, phenylalanine ammonia-lyase; $C 4 H$, cinnamate 4-hydroxylase; $4 C L$, 4-coumarate CoA ligase; TAT, tyrosine amino transferase; $H P P R$, hydroxyl phenylpyruvate reductase; $R A S$, rosmarinic acid synthase (hydroxycinnamoyl-CoA; hydroxyphenyllactate hydroxycinnamoyl transferase); 3-H, 3-hydroxylase; 3'- $H$, 3'hydroxylase 
Environmental factors and cultivation practices affect the production of rosmarinic acid and tilianin in $A$. rugosa. Various strategies, including in vitro cell suspension cultures, Agrobacterium mediated gene transformation, establishment of in vitro cell lines, genetic manipulation, shoot cultivation, bioreactor cultivation, in vitro hairy root cultivation and organ cultivation, have all been shown to improve production of these pharmaceutically important phytochemicals. The process of callus regeneration through tissue culture, for instance, has enormous applications for the bulk production of novel plant metabolites (Razdan, 2003; Kannan and Agastian, 2015). Plant calli are unorganized groups of parenchyma cells which can differentiate into a whole plant through regeneration on media supplemented with plant hormones such as cytokinin and auxin. The levels of plant growth regulators, such as cytokinins, auxins, gibberellins and ethylene, regulate callus formation in cell culture media (Razdan, 2003). Moreover, concentrations of these plant growth regulators can be altered for different plant species, organs, genotypes, ages, nutritional statuses and origins. Other culture conditions, including temperature and light, are also important for callus formation, growth and development. Once established, callus cultures can be used to study processes including protoplast isolation, cell types, cellular selection, somatic embryogenesis, organogenesis and the production of secondary metabolites (Razdan, 2003). Additionally, regenerable calli are a useful tool for genetic transformation (Smith, 2013).

In this study, we investigated the influences of three different LED wavelengths (white, blue and red) on the biosynthesis of phenylpropanoids, including changes in gene expression and variation in the synthesis of rosmarinic acid in A. rugose calli.

\section{Materials and Methods}

\section{Seed sterilization and Germination}

Seeds of Agastache rugosa were purchased from Aram Seed Company (Seoul, Korea). The seeds were surface-sterilized with $70 \%(\mathrm{v} / \mathrm{v})$ ethanol for $1 \mathrm{~min}$ and $4 \%(\mathrm{v} / \mathrm{v})$ sodium hypochlorite solution with a few drops of Tween 20 for $10 \mathrm{~min}$ and then rinsed thrice with sterilized distilled water. Seven seeds were placed on 25 $\mathrm{mL}$ of half strength MS basal solid medium in a culture bottle $(85 \times 105 \mathrm{~mm})$. The basal medium was supplemented with salts and vitamins of MS medium (Murashige and Skoog, 1962), 3\% (w/v) sucrose and solidified with $0.75 \%(\mathrm{w} / \mathrm{v})$ plant agar. The medium was adjusted to $\mathrm{pH} 5.8$ before adding agar and then sterilized in an autoclave at $121^{\circ} \mathrm{C}$ for $20 \mathrm{~min}$. The seeds were germinated in a growth chamber (HB-301L-3, Han Baek Scientific Co, Korea) at $25^{\circ} \mathrm{C}$ under standard cool white fluorescent tube lights with a16 h photoperiod. Plantlets showing ordinary growth rates two weeks after germination were used for callus experiments.

\section{Callus Culture and LED Light Treatments}

The leaves obtained from two-week-old plantlets after in vitro germination were used as the explants to establish callus cultures. Leaf explants were cut aseptically at the ends in to sections of approximately $7 \times 7 \mathrm{~mm}^{2}$ in size and cultured in Petri dishes $(90 \times 15 \mathrm{~mm})$ containing B5 medium supplemented with $2.0 \mathrm{mg} / \mathrm{L} \mathrm{2,4-}$ dichlorophenoxyacetic acid (2,4-D), $0.1 \mathrm{mg} / \mathrm{L}$ kinetin, $3 \%(\mathrm{w} / \mathrm{v})$ sucrose and $0.75 \%(\mathrm{w} / \mathrm{v})$ plant agar. Subcultures of calli (1.5-2 g) were carried out every two weeks. For the study of LED light treatments on $A$. rugosa calli, $0.5 \mathrm{~g}$ (fresh weight) of calli were transferred to $25 \mathrm{~mL}$ of agar-solidified culture medium in petri dishes $(90 \times 15 \mathrm{~mm})$. The basal medium consisted of B5 salts and vitamins, $30 \mathrm{~g} / \mathrm{l}$ sucrose, $2.0 \mathrm{mg} / \mathrm{L} \mathrm{2,4-D,} 0.1$ $\mathrm{mg} / \mathrm{L}$ kinetin, solidified with $0.75 \%$ (w/v) Plant agar. Calli on the Petri dishes were exposed to three different LED colors with a Photosynthetic Photon Flux Density (PPFD) of $150 \mu \mathrm{mol} / \mathrm{m}^{2} / \mathrm{sec}$. Each callus grown under red, blue and white LED light was harvested one to three weeks after LED exposure. The collected calli were frozen in liquid nitrogen and stored at $-80^{\circ} \mathrm{C}$ for further analyses. Each treatment consisted of three Petri dishes and the experiment was repeated in triplicate.

\section{Total RNA Extraction and cDNA Preparation}

Total RNA was extracted from each collected sample using a modified Trizol ${ }^{\circledR}$ method. Harvested plantlet samples were ground finely using a mortar and pestle with liquid nitrogen. One hundred grams of the ground tissue sample were dissolved in $1 \mathrm{~mL}$ Trizol ${ }^{\circledR}$ and added to 200 $\mu \mathrm{L}$ chloroform for phase separation. RNA remains exclusively in the aqueous phase, while DNA and protein contaminants separate into the inter-phase and organic phase, respectively. The aqueous phase was collected and centrifuged at $13,000 \mathrm{rpm}$ in a high speed micro centrifuge (Micro 17TR, Hanil Science Medical, Korea) for $15 \mathrm{~min}$ at $4^{\circ} \mathrm{C}$ to pellet the RNA. Then, the supernatant was discarded and the RNA pellet was washed with $70 \%$ ethanol and re-suspended in DEPC-treated water. Purity of the extracted RNA was determined using a NanoVue ${ }^{\mathrm{TM}}$ Plus Spectrophotometer (GE Healthcare, UK) and formaldehyde RNA agarose gel electrophoresis.

\section{Quantitative Real Time-PCR for Gene Expression Analysis}

The first strand cDNA template was synthesized using 1 $\mu \mathrm{g}$ of total RNA according to manufacturer's instructions (ReverTra Ace ${ }^{\circledR}$, Toyobo, Japan). The reverse-transcribed cDNA products were used as templates for the expression analysis with gene-specific primers (Table 1). 
Table 1: Primers used to qRT-PCR Analysis

\begin{tabular}{|c|c|c|}
\hline Primers & Sequences ( $5^{\prime}$ to $\left.3^{\prime}\right)$ & Amplicon size (bp) \\
\hline Ar Actin $F$ & ACCTCAAAATAGCATGGGGAAGT & 151 \\
\hline Ar Actin $R$ & GGCCGTTCTCTCACTTTATGCTA & \\
\hline Ar PAL F & ACGGCTCCAACGGTCATAATAAT & 108 \\
\hline Ar PAL R & ATCCGCTTTACCTCCTCAAGGT & \\
\hline $\mathrm{ArC} C H \mathrm{H}$ & GTTCGAGAGTGAGAATGATCCGT & 157 \\
\hline $\mathrm{ArC} C H \mathrm{H}$ & ATAATCCTTGAACAATTGCAGCC & \\
\hline Ar HPPR F & AAGGGGATTAGGGTTACCAACACG & 200 \\
\hline Ar HPPR R & ATTCTGCCCAATCCTATGATGCC & \\
\hline Ar TAT F & AGGCAGCAGTACCAGCCATTCTT & 163 \\
\hline Ar TAT R & TTGACCATGAAAGCCATTGATCC & \\
\hline $\operatorname{Ar} R A S F$ & GGCGAACTACCACACGCTGAG & 161 \\
\hline $\operatorname{Ar} R A S R$ & CGATCTCGAGACGGTTATTGTCG & \\
\hline
\end{tabular}

Quantitative real time polymerase chain reaction (qRTPCR) was performed on a CFX96 real time system (BIO-RAD Laboratories, USA) with the 2X Real-Time PCR Smart mix (BioFACT, Korea) under the following conditions: Denaturation at $95^{\circ} \mathrm{C}$ for $15 \mathrm{~min}$, followed by 40 cycles of $95^{\circ} \mathrm{C}$ for $15 \mathrm{sec}$, annealing at $55^{\circ} \mathrm{C}$ for 15 sec and extension at $72^{\circ} \mathrm{C}$ for $20 \mathrm{sec}$. Transcript levels were normalized relative to the housekeeping gene actin. Three replicates per sample were used for real-time PCR and significant differences between treatments were assessed by standard deviation.

\section{Quantification of Phenylpropanoids by HPLC}

For High Performance Liquid Chromatography (HPLC) analysis, samples were freeze-dried in a vacuum for at least $48 \mathrm{~h}$, ground into a fine powder using a mortar and pestle and $100 \mathrm{mg}$ of each sample were mixed with $5 \mathrm{~mL}$ of $100 \%$ methanol for $1 \mathrm{~h}$ at $60^{\circ} \mathrm{C}$ using ultrasonic waves. The phenylpropanoids, namely rosmarinic acid were extracted by methanol. After centrifugation, the supernatant was filtered through a 0.45- $\mu \mathrm{m}$ PVDF filter (Whatman, GE Healthcare, UK) and the extracts were analyzed using a HPLC system (NS-4000, Futecs, Korea). The analysis was performed using a reverse phase $(\mathrm{C} 18,250 \times 4.6 \mathrm{~mm}, 5 \mu \mathrm{m})$ column (prontosil, Bischoff, Germany) at $30^{\circ} \mathrm{C}$ and monitored by a UV detector at $340 \mathrm{~nm}$. The mobile phase was a gradient mixture of absolute methanol and water added to $0.1 \%(\mathrm{v} / \mathrm{v})$ acetic acid. The flow rate was maintained at $1.0 \mathrm{~mL} / \mathrm{min}$ and the injection volume of each sample was $20 \mu \mathrm{L}$. The content of phenylpropanoids in the samples were calculated using a standard curve. Standard compounds were purchased from SigmaAldrich Corporation (USA). Mean values were obtained from three independent replicates.

\section{Statistical Analyses}

For qRT-PCR and HPLC statistical analysis, data were analyzed using SAS® statistical analysis software (SAS version 9.3, SAS Institute Inc., Cary, NC, USA). All data are presented as the average mean and standard deviation of triplicate experiments. The experimental data were subjected to an Analysis Of Variance (ANOVA) and significant differences among group means were determined by Duncan's multiple-range test.

\section{Results and Discussion}

\section{Expression Levels of Phenylpropanoid Gene Relative to LED Light Treatments}

To investigate alterations in expression levels of rosmarinic acid biosynthesis genes in A. rugosa, portions of calli on Petri dishes were exposed to red, blue and white LED light for three weeks and harvested every week after LED exposure. Expression levels were determined by quantitative real-time PCR (Fig. 3). LED lights influenced the expression of different genes in $A$. rugosa calli considerably. Moreover, mRNA transcript levels of downstream genes in the phenylpropanoid pathway ( $C 4 H, H P P R$ and $R A S)$ were higher than those of upstream genes ( $P A L$ and $T A T)$. Expression levels of most genes increased following exposure to LED light. In particular, calli exposed to white LED light transcribed higher levels of mRNA than calli exposed to other wave lengths of LED light (Fig. 3).

$R A S$ transcription was highest two weeks after initial exposure to white LED light. It was 15.7- and 10.4- fold higher than that in calli exposed to red and blue light, respectively. White light also affected $R A S$ expression throughout the duration of the experiment. $R A S$ transcript levels decreased sharply after the third week of exposure to white LED, yet they were 3.3- and 1.4- fold higher than in calli exposed to red and blue LED light, respectively. Gene expression under blue light did not vary during the first week of LED light treatment and there were no significant changes in $R A S$ expression two weeks after initial treatment.

During the first week of exposure to white and blue LED wavelengths, HPPR mRNA transcript levels dramatically increased, with 3.73- and 3.48- fold higher expression than in calli exposed to red light. However, in the second week, expression levels of 
$H P P R$ were similar for all LED wavelengths. White and blue light had analogous effects on week two of LED exposure. In the third week, $H P P R$ transcript levels were 2.43- fold higher in calli exposed to white light than those exposed to blue light. Meanwhile, red light consistently stimulated $H P P R$ transcription during the entire duration of the experiment, although to a lesser degree.

The transcript level of $C 4 H$ increased sharply the first week of exposure to blue and white LED, but decreased comparatively in the second week. White light had a dominant effect on expression of $\mathrm{C} 4 \mathrm{H}$ throughout the experiment. The highest levels of $\mathrm{C} 4 \mathrm{H}$ transcription in calli were found after one week of exposure to white light. It was 11.3- and 1.65- fold

$P A L$

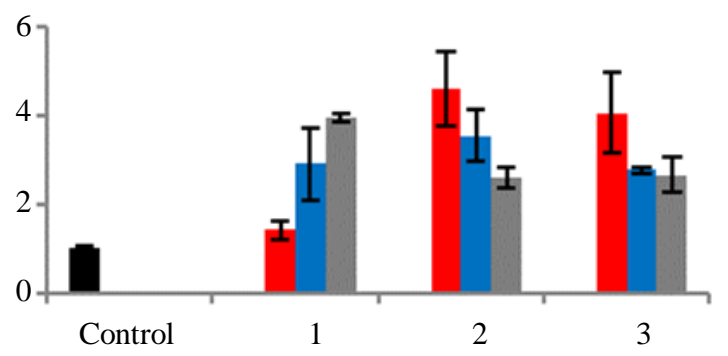

C4H

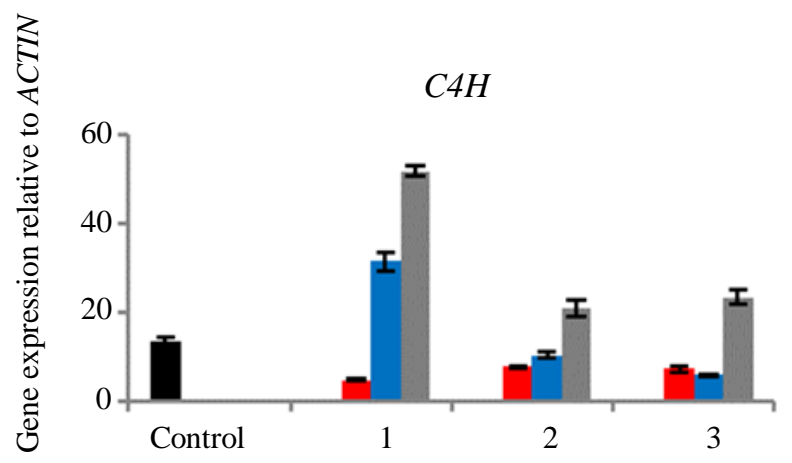

$R A S$

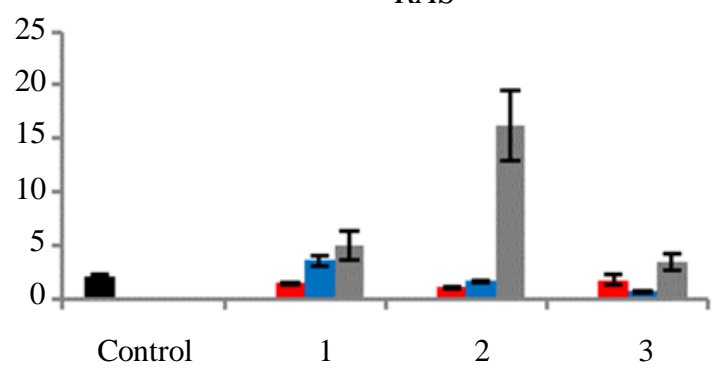

higher than that in calli exposed to red and blue light, respectively. After two weeks, the expression of $\mathrm{C} 4 \mathrm{H}$ in calli exposed to white LED began to decrease, although the levels remained 2.77- and 2.03- fold higher than that in calli exposed to red and blue LED, respectively. Levels of TAT mRNA expressed in calli exposed to blue light were 4.23- to 5.05- fold higher than those in the control group. White LED light demonstrated a lesser effect on TAT expression in calli during the first week. However, white light was associated with increased expression the following two weeks. Indeed, TAT mRNA transcript levels were highest in the first week in calli exposed to blue light. In the second and third weeks, TAT transcript levels were highest in calli exposed to white light.

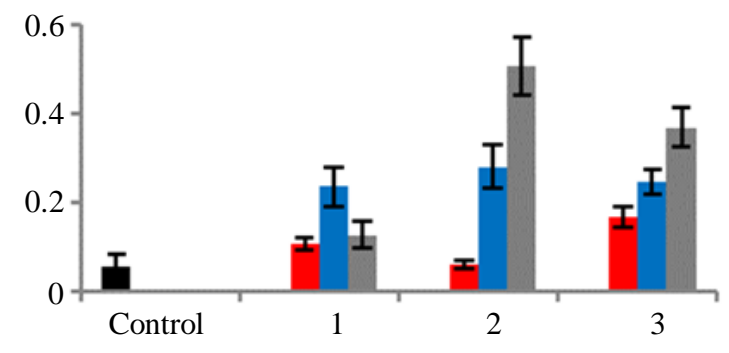

$H P P R$

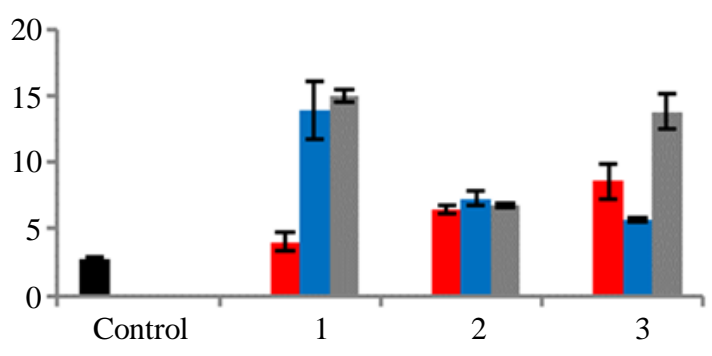

Fig. 3: Expression levels of five rosmarinic acid biosynthesis genes in Agastache rugosa calli grown under different LED light wavelengths. The mRNA transcript levels for each of three experimental groups were analyzed relative to that of actin. Error bars represent standard deviation 


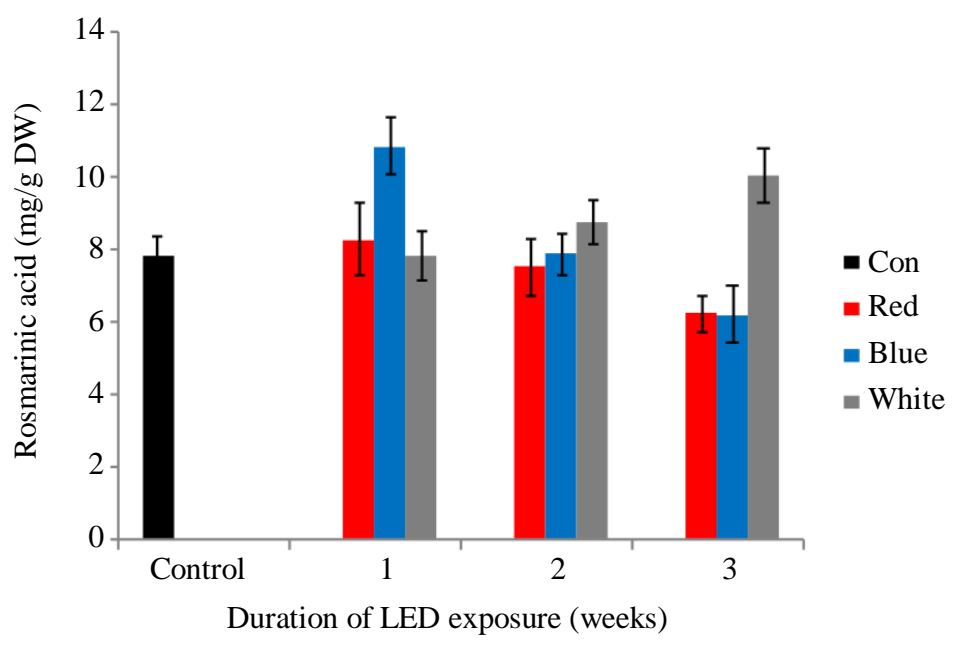

Fig. 4: Content of rosmarinic acid in Agastache rugosa calli grown under LED light of different wavelengths. The levels of accumulated rosmarinic acid in each of the three individual experimental groups were analyzed by HPLC. Error bars represent standard deviation. DW, dry weight.

Although there was no significant change in mRNA transcript levels of $P A L$ among the three wavelengths of light, $P A L$ expression was highest in calli in the second and third weeks of exposure to red LED. Blue light similarly increased transcript levels of $P A L$ during the entire duration of LED treatment, whereas white light altered $P A L$ expression significantly only in the first week of the experiment.

\section{HPLC Analysis of Rosmarinic Acid}

HPLC analysis of A. rugosa calli revealed the presence of rosmarinic acid but not tilianin. Moreover, the accumulation of rosmarinic acid was influenced heavily by LED treatment (Fig. 4). However, amounts of rosmarinic acid in A. rugosa calli and plantlets were not significantly different from one another. The amount of rosmarinic acid in calli peaked after one week of treatment with blue LED light $(10.83 \mathrm{mg} / \mathrm{g})$, demonstrating a 1.39- and 1.31-fold increase over treatments with white and red light, respectively. In contrast, the accumulation of rosmarinic acid in calli exposed to blue LED light began to decrease sharply after two weeks of treatment and in the third week, levels of rosmarinic acid in calli under blue LED light were lower than those in calli exposed to white and red light. White light was less effective in stimulating rosmarinic acid accumulation during the first week of treatment $(7.81 \mathrm{mg} / \mathrm{g})$. However, white light intensified the accumulation of rosmarinic acid in the second week $(8.73 \mathrm{mg} / \mathrm{g})$ and continuously increased to $10.02 \mathrm{mg} / \mathrm{g}$ at the end of the experiment, it was 1.62- and 1.61-fold higher than that in calli exposed to red and blue light, respectively. Accumulation of rosmarinic acid in calli grown under red light was less affected throughout the duration of LED treatment.
In the present study, the optimum wavelengths of LED required for rosmarinic acid biosynthesis were determined by investigating the mRNA transcript levels of rosmarinic acid biosynthesis genes and rosmarinic acid accumulation in callus tissue of $A$. rugosa exposed to red, blue and white LEDs. Most rosmarinic acid biosynthesis genes showed higher expression levels in calli irradiated with white light after the third week of LED treatment. Previously (Karam et al., 2003) reported that a culture duration of five weeks resulted in maximum callus growth and rosmarinic acid yield (2.12 $\mathrm{mg} / 100 \mathrm{mg}$ dry weight), whereas cell suspension growth and rosmarinic acid yield $(5.1 \mathrm{mg} / 100 \mathrm{mg}$ dry weight) reached maximum levels after 20 days of culture. In this study, the highest accumulation of rosmarinic acid was measured in calli grown under white light $(10.02 \mathrm{mg} / \mathrm{g}$ dry weight), higher than that in calli grown under blue and red light (6.22 and $6.21 \mathrm{mg} / \mathrm{g}$, respectively).

Guo et al. (2007) suggested that red light significantly improved callus growth, but inhibited the biosynthesis of flavonoids in callus cultures after 21 days. However, blue light was found to enhance flavonoid biosynthesis, although callus growth under this spectrum was comparable to treatment with white and other colored spectra, including green and yellow. It has also been reported that blue LED light could increases sesamin content of leaves to 2.0- and 4.5 -fold of that by white fluorescent and red LED light, respectively (Hata et al., 2013). A recent study showed chlorogenic acid and rutin content was significantly enhanced in tartary buckwheat sprouts cultivated under red, blue and white LED light and that the amount of cyanidin 3-Orutinoside was dominant in LED treated tartary buckwheat sprouts (Seo et al., 2015). Previously, Awad et al. (2001) reported that chlorogenic acid content is known to be enhanced under blue light (Awad et al, 
2001). In addition, Lee et al. (2014) demonstrated that the production of phenolic compounds, including chlorogenic acid, $C$-glycosyl flavone (orientin, isoorientin, vitexin, iso-vitexin), rutin and quercetin, were moderately increased under red, blue and red and blue mixed LED light treatments (Lee et al., 2014).

\section{Conclusion}

In summary, different LED light wavelengths showed ignificant variance for the accumulation of rosmarinic acid in A. rugosa. Here in this study blue LED light performed betterthan red LED light for enhancing the accumulation of rosmarinic acid. It is mentionable that the increase in rosmarinic acid content and enhanced transcript levels of $C 4 H, H P P R$ and RAS mRNA under white LED light confirmed that these genes have a close relationship and may work together in a pathway to higher rosmarinic acid synthesis. Finally it may be conclude that this study facilitates the development of an effective strategy to maximize the production of rosmarinic acid and other important secondary metabolites in A. rugosa calli using the LED technology.

\section{Acknowledgement}

This research was supported by Basic Science Research Program through the National Research Foundation of Korea (NRF) funded by the Ministry of Education, Science and Technology (20110010231).

\section{Author's Contributions}

Woo Tae Park, Sun Kyung Yeo, Nam Su Kim and Jae Kwang Kim: Performed the experiments, analyzed the data and prepare the manuscript.

Sang Un Park: Designed the experiments, coordinated the implementation of research work.

\section{Ethics}

This manuscript has not been published or presented elsewhere in part or in entirely and is not under consideration by another journal. All the authors have approved the manuscript and agree with submission to your esteemed journal. There are no conflicts of interest to declare.

\section{References}

Abdullah Al-Dhabi, N., M. Valan Arasu and T.S. Rejiniemon, 2015. In vitro antibacterial, antifungal, antibiofilm, antioxidant and anticancer properties of isosteviol isolated from endangered medicinal plant Pittosporum tetraspermum. Evidence-Based Complementary Alternative Medicine.

DOI: $10.1155 / 2015 / 164261$
Al-Dhabi, N.A., M.V. Arasu, C.H. Park and S.U. Park, 2014. Recent studies on rosmarinic acid and its biological and pharmacological activities. EXCLI J., 13: 1192-1195.

Awad, M.A., P.S. Wagenmakers and A. de Jager, 2001. Effects of light on flavonoid and chlorogenic acid levels in the skin of 'Jonagold' apples. Scientia Horticulturae, 88: 289-298. DOI: $10.1016 / \mathrm{S} 0304-4238(00) 00215-6$

Choi, K.S. and H.Y. Lee, 1999. Characteristics of useful components in the leaves of baechohyang (Agastache rugosa, O. Kuntze). J. Korean Soc. Food Sci. Nutr., 28: 326-322.

Gao, L.P., H.L. Wei, H.S. Zhao, S.Y. Xiao and R.L. Zheng, 2005. Antiapoptotic and antioxidant effects of rosmarinic acid in astrocytes. Die Pharmazie-An Int. J. Pharm. Sci., 60: 62-65.

Glorybai, L., M.V. Arasu, N.A. Al-Dhabi and P. Agastian, 2015. Some biological activities of Epaltes divaricata L.-an in vitro study. Annals Clin. Microbiol. Antimicrobials, 14: 18-18.

DOI: 10.1186/s12941-015-0074-4

Gundidza, M., 1993. Antimicrobial activity of essential oil from Schinus molle Linn. Central African J. Med., 39: 231-234.

Guo, B., Y.G. Liu, Q. Yan and C.Z. Liu, 2007. Spectral composition of irradiation regulates the cell growth and flavonoids biosynthesis in callus cultures of Saussurea medusa Maxim. Plant Growth Regulat., 52: 259-263. DOI: 10.1007/s10725-007-9192-0

Hata, N., Y. Hayashi, E. Ono, H. Satake and A. Kobayashi et al., 2013. Differences in plant growth and leaf sesamin content of the lignan-rich sesame variety 'Gomazou'under continuous light of different wavelengths. Plant Biotechnol., 30: 1-8. DOI: $10.5511 /$ plantbiotechnology.12.1021a

Hernández-Abreu, O., P. Castillo-Espana, I. LeónRivera, M. Ibarra-Barajas and R. Villalobos-Molina et al., 2009. Antihypertensive and vasorelaxant effects of tilianin isolated from Agastache mexicana are mediated by NO/cGMP pathway and potassium channel opening. Biochem. Pharmacol., 78: 54-61. DOI: 10.1016/j.bcp.2009.03.016

Hong, J.J., J.H. Choi, S.R. Oh, H.K. Lee and J.H. Park et al., 2001. Inhibition of cytokine-induced vascular cell adhesion molecule-1 expression; possible mechanism for anti-atherogenic effect of Agastache rugosa. FEBS Lett., 495: 142-147. DOI: 10.1016/S0014-5793(01)02379-1

Jiang, C., C.K. Schommer, S.Y. Kim and D.Y. Suh, 2006. Cloning and characterization of chalcone synthase from the moss, Physcomitrella patens. Phytochemistry, 67: 2531-2540.

DOI: $10.1016 /$ j.phytochem.2006.09.030 
Kannan, K.B. and P. Agastian, 2015. In vitro regeneration of a rare antidiabetic plant Epaltes divaricata L. South Indian J. Biol. Sci., 1: 52-59. DOI: 10.22205/sijbs/2015/v1/i1/100445

Karam, N.S., F.M. Jawad, N.A. Arikat and R.A. Shibl, 2003. Growth and rosmarinic acid accumulation in callus, cell suspension and root cultures of wild Salvia fruticose. Plant Cell Tissue Organ Culture, 73: 117-121. DOI: 10.1023/A:1022806310109

Kuroki, G. and J.E. Poulton, 1981. The para-Omethylation of apigenin to acacetin by cell-free extracts of Robinia pseudoacacia L. Zeitschrift für Naturforschung C, 36: 916-920.

DOI: $10.1515 /$ znc-1981-11-1202

Lee, S.W., J.M. Seo, M.K. Lee, J.H. Chun and P. Antonisamy et al., 2014. Influence of different LED lamps on the production of phenolic compounds in common and Tartary buckwheat sprouts. Industrial Crops Prod., 54: 320-326.

DOI: 10.1016/j.indcrop.2014.01.024

Li, F., Z. Jin, W. Qu, D. Zhao and F. Ma, 2006. Cloning of a cDNA encoding the Saussurea medusa chalcone isomerase and its expression in transgenic tobacco. Plant Physiol. Biochem., 44: 455-461. DOI: $10.1016 /$ j.plaphy.2006.08.006

Martens, S. and A. Mithöfer, 2005. Flavones and flavone synthases. Phytochemistry, 66: 2399-2407. DOI: $10.1016 /$ j.phytochem.2005.07.013

Min, B.S., M. Hattori, H.K. Lee and Y.H. Kim, 1999. Inhibitory constituents against HIV-1 protease from Agastache rugosa. Archives Pharm. Res., 22: 75-77. DOI: 10.1007/BF02976440

Nam, K.H., J.H. Choi, Y.J. Seo, Y.M. Lee and Y.S. Won et al., 2006. Inhibitory effects of tilianin on the expression of inducible nitric oxide synthase in low density lipoprotein receptor deficiency mice. Exp. Molecular Med., 38: 445-452.

DOI: $10.1038 / \mathrm{emm} .2006 .52$

Ogata, J., Y. Itoh, M. Ishida, H. Yoshida and Y. Ozeki, 2004. Cloning and heterologous expression of cDNAs encoding flavonoid glucosyltransferases from Dianthus caryophyllus. Plant Biotechnol., 21: 367-375.

DOI: $10.5511 /$ plantbiotechnology.21.367

Petersen, M.S., 1991. Characterization of rosmarinic acid synthase from cell cultures of Coleus blumei. Phytochemistry, 30: 2877-2881. DOI: 10.1016/S0031-9422(00)98217-7

Petersen, M., 1997. Cytochrome P450-dependent hydroxylation in the biosynthesis of rosmarinic acid in Coleus. Phytochemistry, 45: 1165-1172.

DOI: 10.1016/S0031-9422(97)00135-0

Razdan, M.K., 2003. Introduction to Plant Tissue Culture. 2 Edn., Oxford and IBH Publishing.
Rejiniemon, T.S., M.V. Arasu, V. Duraipandiyan, K. Ponmurugan and N.A. Al-Dhabi et al., 2014. Invitro antimicrobial, antibiofilm, cytotoxic, antifeedant and larvicidal properties of novel quinone isolated from Aegle marmelos (Linn.) Correa. Annals Clin. Microbiol. Antimicrobials, 13: 48-48. DOI: 10.1186/s12941-014-0048-y

Seo, J.M., M.V. Arasu, Y.B. Kim, S.U. Park and S.J. Kim, 2015. Phenylalanine and LED lights enhance phenolic compound production in Tartary buckwheat sprouts. Food Chem., 177: 204-213. DOI: 10.1016/j.foodchem.2014.12.094

Smith, R.H., 2013. Explant Preparation. In: Plant Tissue Culture: Techniques and Experiments, R.H. Smith (Ed.), Academic Press, Waltham, MA, USA, ISBN-13: 978-0-12-415920-4, pp: 45-51.

Shin, S. and C.A. Kang, 2003. Antifungal activity of the essential oil of Agastache rugosa Kuntze and its synergism with ketoconazole. Lett. Applied Microbiol., 36: 111-115.

DOI: 10.1046/j.1472-765X.2003.01271.x

Song, J.H., M.J. Kim, H.D. Kwon and I.H. Park, 2001. Antimicrobial activity and components of extracts from Agastache rugosa during growth period. J. Food Sci. Nutr., 6: 10-15.

Swarup, V., J. Ghosh, S. Ghosh, A. Saxena and A. Basu, 2007. Antiviral and anti-inflammatory effects of rosmarinic acid in an experimental murine model of Japanese encephalitis. Antimicrobial Agents Chemotherapy, 51: 3367-3370.

DOI: 10.1128/AAC.00041-07

Vogt, T., 2010. Phenylpropanoid biosynthesis. Molecular Plant, 3: 2-20. DOI: 10.1093/mp/ssp106

WHO, 2002. WHO traditional medicine strategy 20022005. World Health Organization, Geneva.

Yamani, H., N. Mantri, P.D. Morrison and E. Pang, 2014. Analysis of the volatile organic compounds from leaves, flower spikes and nectar of Australian grown Agastache rugosa. BMC Complementary Alternative Med., 14: 1-6.

DOI: $10.1186 / 1472-6882-14-495$

Zhao, S., P.A. Tuan, X. Li, Y.B. Kim and H. Kim et al., 2013. Identification of phenylpropanoid biosynthetic genes and phenylpropanoid accumulation by transcriptome analysis of Lycium chinense. BMC Genom., 14: 802-802.

DOI: $10.1186 / 1471-2164-14-802$ 